\title{
Spontaneous Pneumomediastinum in a Term Neonate: A Case Report
}

\author{
Mawlana WH, ${ }^{1,2 *}$, Osman $\mathrm{A}^{2}$ and Toonisi MA ${ }^{2}$ \\ ${ }^{1}$ Department of Pediatrics and Neonatology, Tanta \\ University Hospital, Egypt \\ ${ }^{2}$ Department of Pediatrics and Neonatology, King Salman \\ Armed Forces Hospital, Saudi Arabia \\ *Corresponding author: Wegdan Helmy Mawlana, \\ Department of Pediatrics and Neonatology, Tanta \\ University Hospital, Tanta, Egypt
}

Received: March 09, 2021; Accepted: March 18, 2021; Published: March 25, 2021

\section{Introduction}

Pneumomediastinum is uncommon cause of respiratory distress in term infants. The actual incidence is unknown since most of those infants are asymptomatic [1]. Term infants with meconium aspiration syndrome, pneumonia, vigorous resuscitation at birth, lung hypoplasia and ventilator support are at high risk [2]. We report a clinical case of term infant with significant pneumomediastinum without identifiable risk factors.

\section{Case Presentation}

A term baby boy with gestational age $38+6$ weeks was born by spontaneous vaginal delivery to 28 years old G2P1 Saudi female. His birth weight was $2.5 \mathrm{~kg}$ with APGAR score 8 and 9 at 1 and 5 minutes respectively. He did not require any resuscitation. Shortly after birth he developed grunting with mild respiratory distress, so he was kept in the nursery under observation with oxygen supply by nasal cannula for 2 hours but with no improvement so he was admitted to our NICU for further investigations.

On admission baby looks well, active, not dysmorphic, vitally stable, chest examination showed grunting with fair air entry bilaterally. Other systemic exam unremarkable. Chest $\mathrm{x}$ - ray done at 3 hours of life showed significant pneumomediastinum with spinnaker-sail sign (Figure 1). Capillary blood gas was normal ( $\mathrm{pH}$ 7.33, $\mathrm{Pco} 240, \mathrm{Hco} 318, \mathrm{BE}-3$ ). $\mathrm{SO}_{2}$ was $>95 \%$ on nasal cannula oxygen saturation of 21 to $25 \%$. His respiratory distress improved dramatically with gradual weaning of nasal cannula oxygen by the second day of life. Because of significant pneumomediastinum as shown in the first $\mathrm{x}$-ray, he was kept under close observation and follow up with serial $\mathrm{x}$-rays till day 9 of life (Figure 2,3). It showed persistent same radiologic finding with no regression (Figure 4). For that, CT chest was done that confirmed the same finding with no other abnormalities. On admission white cell blood count was normal and blood culture was sterile. Baby was discharged home on day 10 of life with follow up after 2 weeks. Repeated X-ray done then showed resolved pneumomediastinum.

\section{Discussion}

A pneumomediastinum is air dissecting into the hilum through

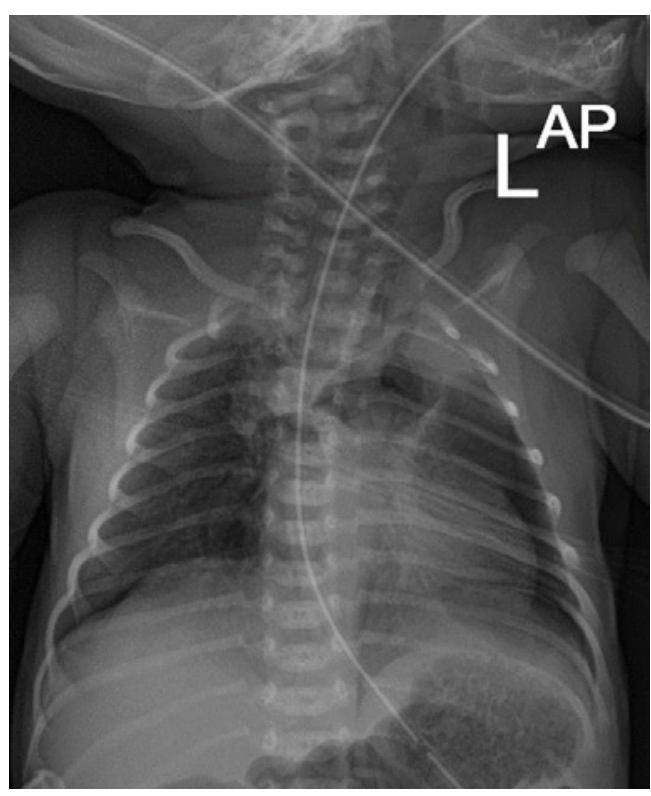

Figure 1: Plain radiograph of the chest, showing the Spinnaker-Sail Sign. Both lobes of the thymus are lifted and displaced into the upper mediastinum creating a wedge-shaped opacity. This resembles a Spinnaker sail.

the perivascular sheaths from ruptured alveolar air into the mediastinum [3]. It has been estimated to occur spontaneously in 25 of 10,000 live births in asymptomatic infants [4]. Apparent risk factors included vigorous resuscitation, mechanical ventilation, meconium aspiration syndrome and prematurity [5]. Interestingly, our case has no identifiable risk factors. Our baby boy was born at term by spontaneous vaginal delivery, did not receive any resuscitation, only required nasal cannula oxygen for few hours. This could be explained by the pressure gradient between the alveolar and perivascular space that could be abnormally high during crying of the baby and an alveolar rupture may occur [6]. Chest x-ray is usually enough to diagnosis pneumomediastinum, it may show a halo around the heart border or air elevating the thymus and giving rise to a crescentic configuration and a windblown spinnaker sail as in our patient $[7,8]$.

Conservative management and close observation is the standard 


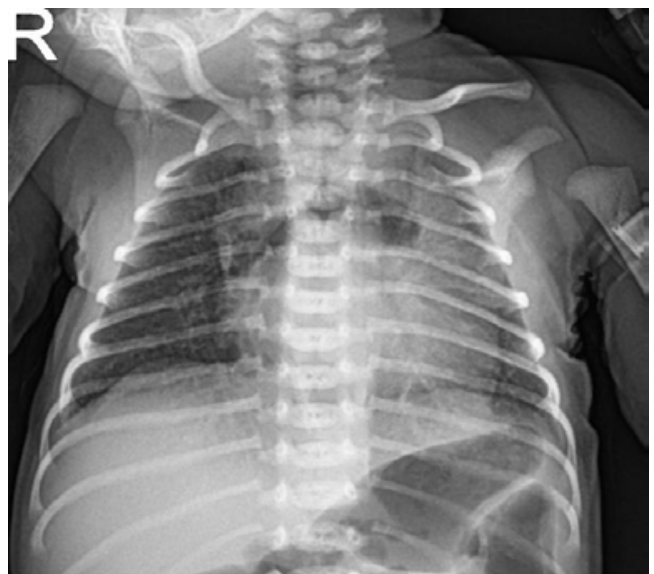

Figure 2: Plain radiograph of the chest, showing the Spinnaker-Sail Sign.

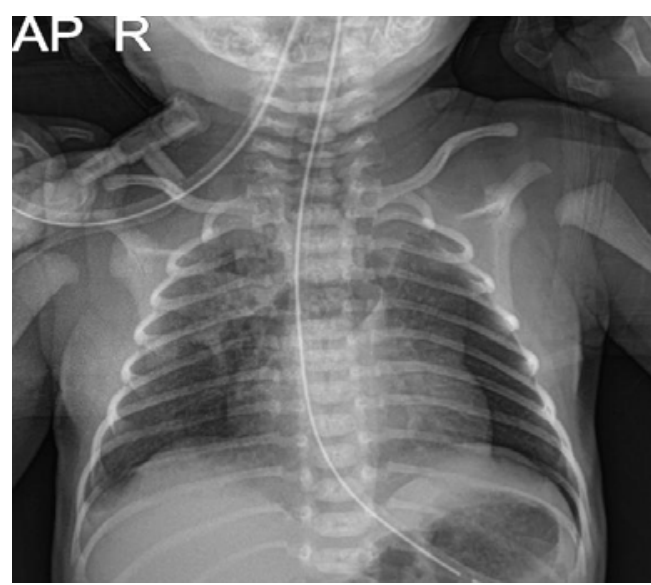

Figure 3: Plain radiograph of the chest, showing the Spinnaker-Sail Sign.

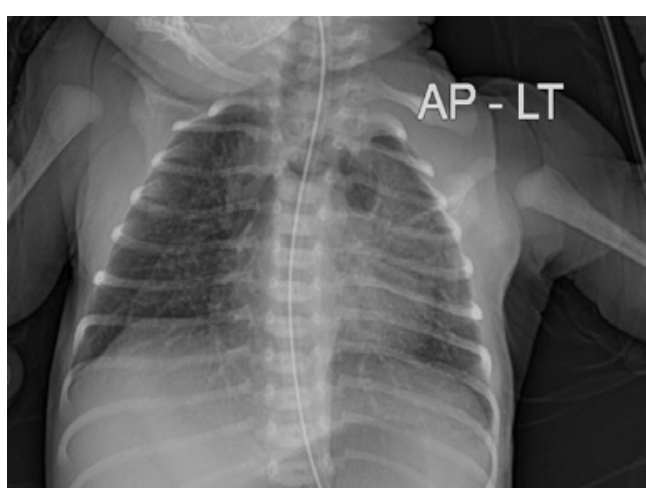

Figure 4: Frontal plain radiograph of the chest, showing the SpinnakerSail Sign. Both lobes of the thymus are lifted and displaced into the upper mediastinum, creating a wedge-shaped opacity. This resembles a Spinnaker sail. of care in almost all cases as the majority of them show spontaneous resolution [9]. However some cases may be presented with severe respiratory distress that require high frequency ventilation [10]. Few reported cases required drainage [11]. Luckily our baby was in room air with no signs of distress on the second day. Because of the potential risk of deterioration of the clinical status; pneumothorax, subcutaneous, and interstitial emphysema he was kept under observation with repeated chest $\mathrm{x}$-rays that showed persistent pneumomediastinum till day nine of life, so CT chest was done to exclude any other anomalies. Chest CT confirmed the same finding. Baby was discharged home on day ten of life. He was examined after 2 weeks, he was doing well and chest $\mathrm{x}$-ray showed resolved pneumomediastinum.

\section{Conclusion}

Pneumomediastinum can occur in term infants with no identified risk factors. Most of them resolve spontaneously.

\section{Informed Consent}

Written informed consent from the parent was obtained for the publication of this case.

\section{References}

1. Franco L, Vieira F, Tuna M. Neonatal spontaneous pneumomediastinum. Lung. 2014; 192: 819-820.

2. Kouritas VK, Papagiannopoulos K, Lazaridis G, Baka S, Mpoukovinas I Karavasilis V, et al. Pneumomediastinum. J Thorac Dis. 2015; 7: S44-S49.

3. Corsini I, Dani C. Pneumomediastinum in term and late preterm newborns: what is the proper clinical approach?. J MaternFetal Neonatal Med. 2015 28: 1332-1335.

4. Zenk KE. Air leak syndromes. Editors. In: Gomella TL, Cunningham MD, Eyal FG. Neonatology-management, procedures, on-call problems, diseases, and drugs, $8^{\text {th }}$ edition. McGraw-Hill Education, New York. 2020; 549-557.

5. Chan C, Hsu Y, Lim K, Chang H, Kuo H, Tsai Y. Spontaneous pneumomediastinum in a neonate: a rare complication of vaginal delivery. Clin J Radiol. 2008; 33: 277-280.

6. Rocha G, Guimaraes H. Spontaneous pneumomediastinum in a term neonate -case report. Clin Case Rep 2018; 6: 314-316.

7. Monteiro R, Paulos L, Agro Jdo, Winckler L. Neonatal spontaneous Pneumomediastinum and the Spinnaker-Sail sign. Einstein. 2015; 13: 642643.

8. Vanden Berghe S, Devlies F, Seynaeve P. The Spinnaker-Sail Sign: Neonata Pneumomediastinum. Journal of the Belgian Society of Radiology. 2018; 102 51.

9. Teo S, Priyadarshi A, Carmo K. Sail sign in neonatal pneumomediastinum: a case report. BMC Pediatrics. 2019; 19: 38.

10. Raissaki M, Modatsou E, Hatzidaki E. Spontaneous pneumomediastinum in a term newborn: atypical radiographic and CT appearance .Case Rep. 2019; 5: 20180081.

11. Jeong JY, Nam SW, Je BK, Choi BM. Tension pneumomediastinum with subcutaneous emphysema. Arch Dis Child Fetal Neonatal Ed. 2011; 96: F448-F449. 